\title{
Study of methacholine positivity in patients with chronic cough at Masih Daneshvari hospital, Tehran, 2007-2008
}

A. Cheraghvandi, ${ }^{1}$ L. Fadaizadeh, ${ }^{2}$ S.A. Taheri ${ }^{3}$ and M. R. Masjedi ${ }^{4}$

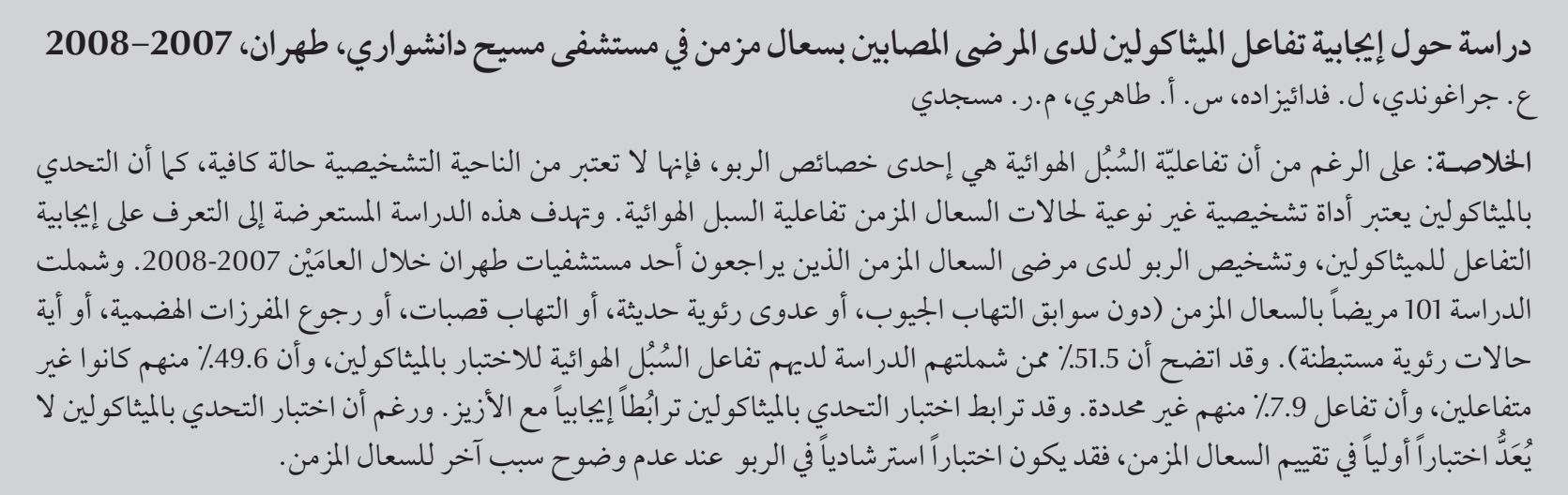

ABSTRACT While airways reactivity is among the characteristics of asthma, it is not considered a sufficient condition diagnostically and the methacholine challenge is a non-specific diagnostic aid in cases of chronic cough and reactive airways disease. The aim of this cross-sectional study was to determine the metacholine response positivity and diagnosis of asthma in patients with chronic cough presenting to a hospital in Tehran during 2007 and 2008. Of 101 patients with chronic cough (with no history of sinusitis, recent pulmonary infection, bronchitis, gasteroesophageal reflux or underlying pulmonary conditions), 51.5\% showed reactive airways disease to the methacholine test, $40.6 \%$ were unreactive and $7.9 \%$ were indeterminate. A positive methacholine challenge test was positively correlated with new wheezing. Although the methacholine challenge test is not a primary test for evaluating chronic cough, if no other reason for chronic cough is found, it may be a guiding test for asthma.

Étude de la positivité à la méthacholine chez des patients souffrant de toux chronique à I'hôpital Masih Daneshvari de Téhéran entre 2007 et 2008

RÉSUMÉ Si la réactivité des voies aériennes compte parmi les caractéristiques de l'asthme, elle n'est pas considérée comme suffisante pour poser un diagnostic; la provocation à la méthacholine est une aide non spécifique pour le diagnostic dans les cas de toux chronique et d'hyperréactivité des voies aériennes. La présente étude transversale visait à déterminer la positivité à la méthacholine et le diagnostic d'asthme des patients souffrant de toux chronique ayant consulté dans un hôpital de Téhéran entre 2007 et 2008 . Sur un total de 101 patients atteints de toux chronique (sans antécédents de sinusite, d'infection pulmonaire récente, de bronchite, de reflux gastro-oesophagien ni d'affections pulmonaires sous-jacentes), 51,5\% ont présenté une hyperréactivité des voies aériennes au test de provocation à la méthacholine, 40,6\% n'ont pas eu de réaction et 7,9\% ont eu des résultats non concluants. Un résultat positif au test de provocation à la méthacholine était positivement corrélé à la survenue d'un sifflement. Le test de provocation à la méthacholine ne représente pas le test principal permettant d'évaluer une toux chronique mais peut toutefois être utile pour établir le diagnostic d'asthme si aucune autre cause n'est identifiée pour la toux chronique. 


\section{Introduction}

One of the characteristics of most asthmatic patients is cough and increased airways responsiveness on exposure to selected allergens. Yes, while airways reactivity is among the characteristics of asthma, it is not considered a sufficient condition diagnostically. It is also not clear which comes first, control of bronchial diameter or hyper-reactivity [1].

The methacholine challenge test is a non-specific diagnostic aid in cases of chronic cough and reactive airways disease. In a report by Wongtim et al. the methacholine test was shown to have an important role in reaching a diagnosis in patients with chronic cough and its positive predictive value for asthma was $60 \%-82 \%$ [2]. In another large study in Australia with 876 participants, $81 \%$ had hyper-responsiveness to inhaled histamine while only $6 \%$ were diagnosed with asthma based on reactivity of the airways [3]. In a similar study of airways reactivity linked to various occupations it was demonstrated that hyper-reactivity was much more common than what could be medically termed asthma $[4,5]$. It seems therefore that airways hyper-reactivity is only one part of asthma and can also be a cause of chronic cough. As a result, it is prudent to look for other reasons for airways reactivity and not attribute it only to asthma. Specific and non-specific tests can be helpful in this endeavour. Studies concerning cough and asthma are few and we planned this study to determine the prevalence of asthma among patients with symptoms of cough who had an extensive work-up for this condition. Patients in whom a definite diagnosis using clinical symptoms or spirometry results could not be reached were invited to participate in the methacholine challenge test.

\section{Methods}

\section{Sample}

This was a cross-sectional study of patients with chronic cough during the years 2007 and 2008. All patients over the 2-year period who presented with chronic cough and who met the inclusion criteria were included in the study. The inclusion criteria were chronic cough of more than 3 weeks duration, cough without a known cause, age above 10 years and normal radiography of the chest, sinuses and spirometry. Exclusion criteria were all patients with asthma, pulmonary infections, gastroesophageal reflux, foreign body aspiration, recent upper respiratory infections (within 8 weeks), chronic bronchitis, sinusitis or other pulmonary conditions or symptoms consistent with airways disease such as wheezing.

\section{Data collection}

Patients were advised not to take methacholine, theophylline, antihistamines, $\beta_{2}$-agonists, sympathomimetics or anticholinergic medications for 48 hours before the test. The methacholine test was performed according to the following pulmonary laboratory protocol.

A spirometry test was performed and if the patient's forced expiratory volume in $1 \mathrm{sec}$ (FEV1) was above $70 \%$ of expected, saline nebulizer treatment was given for 2 minutes. After 3 minutes rest the patient underwent a spirometry test. If FEV1 did not drop by $20 \%$, treatment with methacholine was started. The first concentration of the methacholine nebulizer was 0.03 $\mathrm{mg} / \mathrm{mL}$ for 2 minutes, after which 3 minutes of rest was given and spirometry was performed again. If there was no drop in FEV1 below 20\%, testing was continued with double doses of methacholine until one of these occurred: a drop in FEV1 20\% below the first FEV1 or a dose of $16 \mathrm{mg} /$ $\mathrm{mL}$ methacholine was reached. If a patient developed coughing, shortness of breath or wheezing, the test was ended and considered positive.

A drop in FEV1 of $20 \%$ was considered positive for airways hyperreactivity, $16 \%$ was considered negative and between $16 \%-20 \%$ was considered indeterminate and the test was repeated after 2 weeks.

\section{Data analysis}

Information from the patient's history, physical examination and the methacholine test results were analysed statistically using the chi-squared test. Statistical analysis was done using SPSS, version 9 .

\section{Results}

A total of 101 participants met the inclusion criteria (51 men and 50 women), with a mean age of 38.8 [standard deviation (SD) 15.4] years, range 14-74 years.

All patients had a history of cough of more than 3 weeks. Other clinical symptoms, summarized in Figure 1, showed that $61.4 \%$ had shortness of breath, $52.5 \%$ had paroxysmal nocturnal dyspnoea and $48.5 \%$ had sputum production. Of the total patients $9.9 \%$ were smokers but none reported being substance abusers. At study entry none of them had other pulmonary diseases, sinusitis, recent cold (past 8 weeks) and wheezing on auscultation. In their past medical history 32 individuals (31.7\%) reporting having had sinusitis, $9.9 \%$ eczema and $4.0 \%$ acute bronchitis.

The final results of the methacholine challenge test showed 52 cases were positive (51.5\%), 8 were indeterminate (7.9\%) and 41 were negative (40.6\%). The rate of airways reactivity was higher among women (58.0\%) compared with men $(45.1 \%)$ but this was not statistically significant (Table 1 ). The mean methacholine concentration in the nebulizer that gave positive test results was $7.8(\mathrm{SD} 6.9) \mathrm{mg} / \mathrm{mL}$, range 0.06 to $16 \mathrm{mg} / \mathrm{mL}$. Of the individuals with a positive test, $42 / 52(80.8 \%)$ had a 20\% decrease in FEV1, 9 (17.3\%) had wheezing and 1 (1.9\%) developed severe coughing and the test was discontinued. Patients with positive tests were prescribed bronchodilators. Of the 8 


\begin{tabular}{|c|c|c|c|c|c|c|c|}
\hline \multicolumn{8}{|c|}{$\begin{array}{l}\text { Table } 1 \text { Distribution of patients with chronic cough based on response to the methacholine challenge test, Masih Daneshvari } \\
\text { hospital, 2007-2008 }\end{array}$} \\
\hline \multirow[t]{3}{*}{ Sex } & \multicolumn{7}{|c|}{ Response } \\
\hline & \multicolumn{2}{|c|}{ Positive } & \multicolumn{2}{|c|}{ Negative } & \multicolumn{2}{|c|}{ Indeterminate } & \multirow[t]{2}{*}{ Total } \\
\hline & No. & $\%$ & No. & $\%$ & No. & $\%$ & \\
\hline Male & 23 & 45.1 & 25 & 49.0 & 3 & 5.9 & 51 \\
\hline Female & 29 & 58.0 & 16 & 32.0 & 5 & 10.0 & 50 \\
\hline Total & 52 & 51.5 & 41 & 40.6 & 8 & 7.9 & 101 \\
\hline
\end{tabular}

patients who had indeterminate test results, none returned for retesting and a definite diagnosis was not possible.

The mean fall in FEV1 on challenge was 21.4 (SD 8.7) L, for FVC was 14.7 (SD 9.4) $\mathrm{L}$ and for peak expiratory flow (PEF) was 19.8 (SD 6.1) L/min. On receiving a bronchodilator, the mean increase in FEV1 was 15.7 (SD 9.5) L, FVC 8.7 (SD 5.9) L and PEF was 6.1 (SD 18.6) L/min.

The chi-squared test showed that only a positive methacholine challenge test had a positive correlation with the presence of wheezing $(P<0.001)$ but not with any other symptoms (including bronchitis, eczema and sinusitis) [data not shown]. Only 10 individuals were smokers and therefore no statistical conclusions could be reached about the influence of smoking.

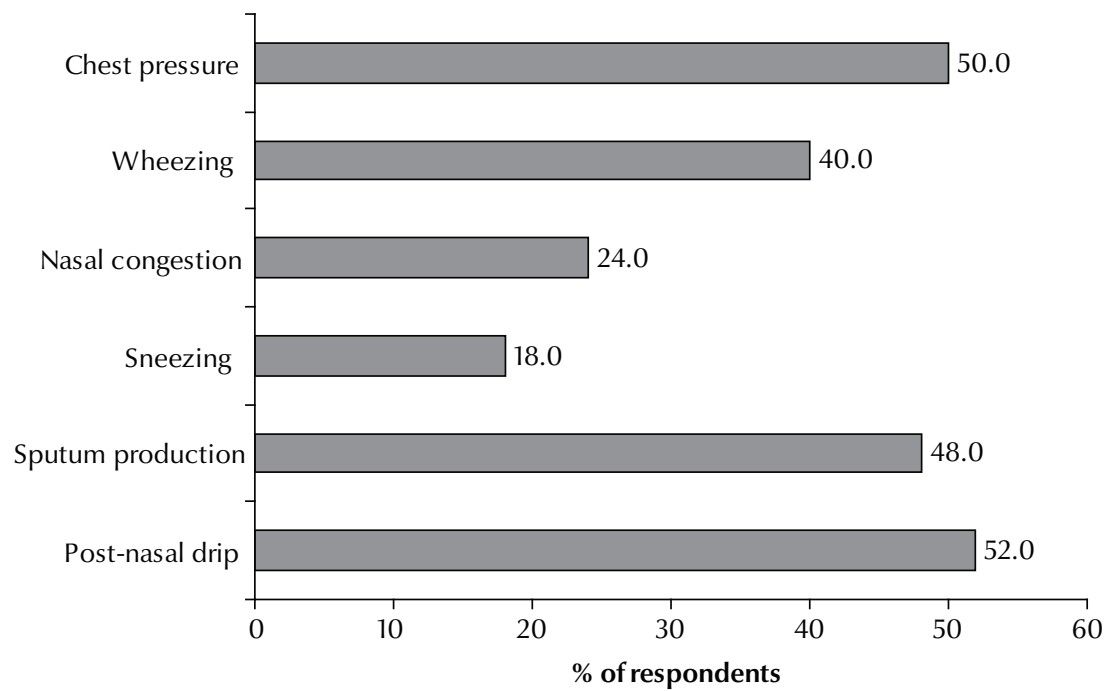

Figure 1 Clinical symptoms of 101 patients with chronic cough, Masih Daneshvari hospital, 2007-2008

\section{Discussion}

In this study 101 participants with chronic cough underwent the methacholine challenge test. The results showed that $52(51.5 \%)$ of them had airways hyper-reactivity to the test, which is comparable to the results from similar studies [6-9]. Patients with chronic cough may show hyperreactivity significant enough to undergo more complete evaluation. The average dose of methacholine that led to positive test was $7.8(\mathrm{SD} 6.9) \mathrm{mg} / \mathrm{mL}$, which is similar to these other studies. A positive methacholine test at doses $<8 \mathrm{mg} / \mathrm{mL}$ (proactive concentration) may therefore be a good marker for diagnosis of asthma [1].

The rate of airways reactivity was higher in women than men $(58.0 \%$

versus $45.1 \%$ ) but this was not statistically significant. While a similar result has been found in some studies [10-13], other studies do not support this finding $[14,15]$.

In this study, only a positive methacholine challenge test had a positive correlation with wheezing, which could be sign of airways hyperreactivity that is not seen with other symptoms. Individuals with sinusitis, eczema and acute bronchitis did not show a positive methacholine challenge test and a history of such conditions may not influence airways hyper-reactivity.

During the methacholine challenge test, the average drop in FEV1 for positive tests for these patients was 21.4 (SD 8.6) L and the increase after bronchodilator administration was 15.7 (SD 9.5) L, which can be a sign of bronchial asthma [1]. A 16\% improvement in FEV1 using a bronchodilator is an indicator of effective therapeutic response.

In conclusion, even though the methacholine challenge test is not a primary test for evaluating chronic cough it may be a guiding test for asthma, if no other reason for chronic cough is found.

\section{Acknowledgements}

The authors would like to thank all colleagues at Masih Daneshvari Hospital who helped with the preparation of this manuscript.

Competing interests: Nonedeclared. 


\section{References}

1. Fraser M, Colman P, editors. Diagnosis of diseases of the chest 4th ed. Philadelphia, Pennsylvania, WB Saunders, 1999:380382;420-423.

2. Wongtim $S$ et al. The role of the methacholine inhalation challenge in adult patients presenting with chronic cough. Asian Pacific Journal of Allergy and Immunology, 1997, 15:9-14.

3. Woolcock AJ et al. Prevalence of bronchial hyperresponsiveness and asthma in a rural adult population. Thorax, 1987, 42:361-368.

4. Weiss ST et al. Airways responsiveness in a population sample of adults and children. American Review of Respiratory Disease, 1984, 129:898-902.

5. Mortagy AK, Howell JBL, Waters WE. Respiratory symptoms and bronchial reactivity: identification of a syndrome and its relation to asthma. British Medical Journal, 1986, 293:525-529.

6. Irwin RS et al. Interpretation of positive results of a methacholine inhalation challenge and 1 week of inhaled bronchodilator use in diagnosing and treating cough-variant asthma. Archives of Internal Medicine, 1997, 157:1981-1987.

7. Koh YY, Chae SA, Min KU. Cough variant asthma is associated with a higher wheezing threshold than classic asthma. Clinical and Experimental Allergy, 1993, 23:696-701.

8. Corrao WM. Methacholine challenge in the evaluation of chronic cough. Allergy Proceedings, 1989, 10:313-315.
9. Irwin RS, Curley FJ, French CL. Chronic cough. The spectrum and frequency of causes, key components of the diagnostic evaluation, and outcome of specific therapy. American Review of Respiratory Disease, 1990, 141:640-647.

10. Wassmer $\mathrm{G}$ et al. The association between baseline lung function and bronchial responsiveness to methacholine. European Journal of Medical Research, 1997, 2:47-54.

11. Abramson $\mathrm{M}$ et al. Risk factors for asthma among young adults in Melbourne. Australia Respirology, 1996, 1(4):291-297.

12. Kanner RE et al. Gender difference in airway hyperresponsiveness in smokers with mild COPD. The Lung Health Study. American Journal of Respiratory and Critical Care Medicine, 1994, 150:956-961.

13. Larsson L, Boëthius G, Uddenfeldt M. Differences in utilisation of asthma drugs between two neighbouring Swedish provinces: relation to prevalence of obstructive airway disease. Thorax, 1994, 49:41-49.

14. Hedman J, Poussa T, Nieminen MM. A rapid dosimetric methacholine challenge in asthma diagnostics: a clinical study of 230 patients with dyspnoea, wheezing or a cough of unknown cause. Respiratory Medicine, 1998, 92:32-39.

15. Martin RJ et al.; Asthma Clinical Research Network (ACRN). Methacholine challenge testing: safety of low starting FEV1. Chest, 1997, 112:53-56. 